\title{
$\alpha$-Secretase ADAM10 as Well as $\alpha$ APPs Is Reduced in Platelets and CSF of Alzheimer Disease Patients
}

\author{
Francesca Colciaghi, ${ }^{1}$ Barbara Borroni, ${ }^{2}$ Lucia Pastorino, ${ }^{1}$ Elena Marcello, ${ }^{1}$ Martina Zimmermann, \\ Flaminio Cattabeni, ${ }^{1}$ Alessandro Padovani, ${ }^{2}$ and Monica Di Luca ${ }^{1}$ \\ ${ }^{1}$ Centre of Excellence on Neurodegenerative Diseases and Department of Pharmacological Sciences, \\ University of Milano, School of Pharmacy, Milano, Italy \\ ${ }^{2}$ Department of Medical Sciences-Neurology Unit, University of Brescia School of Medicine, Brescia, Italy \\ Accepted January 28, 2002
}

\begin{abstract}
Background: Members of membrane-bound disintegrin metalloproteinases (ADAMs) were shown to be capable of cleaving amyloid precursor protein (APP) at the $\alpha$ cleavage site in different cell systems. One of the candidate $\alpha$-secretases identified in this family is ADAM10. The present study addresses the following major questions: 1) Are the levels of an $\alpha$-secretase candidate (i.e., ADAM10) reduced in accessible cells of Alzheimer Disease (AD) patients? 2) Are ADAM10 levels in the peripheral cells of $\mathrm{AD}$ patients related to a concomitant decrease in $\alpha$ APPs?

Materials and Methods: Western Blot analysis of ADAM10 is performed on platelet homogenates from 33 sporadic $\mathrm{AD}$ patients and on 26 age-matched control subjects. Moreover, the levels of $\alpha$-secretase metabolite ( $\alpha$ APPs) are tested both in platelets and cerebrospinal
\end{abstract}

fluid (CSF) of the same pool of subjects by means of Western blot with a specific antibody.

Results: A significant decrease of platelet ADAM10 levels is observed in patients affected by probable AD when compared to control subjects and this is paralleled by a reduced level of $\alpha$ APPs released from platelets. Moreover, in the same pool of AD patients, $\alpha$ APPs levels were reduced concomitantly in CSF.

Conclusions: ADAM10 is expressed in platelets. A reduced level of ADAM10 is observed in platelets obtained from AD patients compared to age-matched controls. Further, in the same pool of AD patients, a qualitatively and quantitatively similar decrease in $\alpha$ APPs is present both in thrombin-activated platelets and CSF, thus suggesting that alterations of APP processing might occur both in the neuronal compartment and peripheral cells.

\section{Introduction}

The amyloid precursor protein (APP) is a crucial element in the amyloid cascade and in the pathogenesis of Alzheimer Disease (AD). It can be processed by different pathways involving either $\alpha, \beta$, or $\gamma$ cleavage. The major physiologic route involves cleavage by $\alpha$-secretase along the secretory pathway from the Golgi to the plasma membrane (1-5). The $\alpha$-secretase cleavage occurs within the amyloid (A $\beta)$ domain of APP and results in the secretion of the large and soluble extracellular domain of APP, the so-called $\alpha$ APPs. Although numerous cells possess a basal level of $\alpha$-secretase activity, proteolysis of APP by this enzyme is enhanced by diverse intracellular pathways such as activation of protein kinase $\mathrm{C}$ (PKC) (6). Accordingly, activation of membrane receptors coupled to PKC has been shown to increase APP $\alpha$-secretase cleavage (7). In addition, experimental evidence suggests that $\alpha$ APPs may exert a neuroprotective effect and may enhance learning

Correspondence and reprint requests should be addressed to: Monica Di Luca, PhD; Department of Pharmacological Sciences, University of Milano, Via Balzaretti, 9, 20133 Milano, Italy. Phone: +39-02-50318374; fax: +39-02-50318284;

e-mail: Monica.Diluca@unimi.it and memory processes. Thus, the regulation of APP metabolism through $\alpha$-secretase pathway appears to be relevant for the pathogenesis of AD.

Members of membrane-bound disintegrin metalloproteinases (ADAMs) were shown to be capable of cleaving APP at the $\alpha$ cleavage site in different cell systems. The candidate $\alpha$-secretases identified so far are ADAM $9(8,9)$, ADAM10 $(10,11)$, and ADAM17 (also known as TACE) $(6,12)$. Although all these proteases share common structural homologies and are sensitive to peptide hydroxamates (13), there is evidence that ADAM17 does not posses inducible $\alpha$-secretase activity (6), and that only ADAMI0 shows basal and PKCstimulated $\alpha$-secretase activity, as well as other properties expected for the proteolytic processing of APP (10).

Because the $\alpha$-secretase and the amyloidogenic $\beta$-secretase pathways were shown to be mutually exclusive (7), evaluating $\alpha$-secretase activity in patients is crucial to understanding its role in the pathogenesis of $\mathrm{AD}$.

To this end, we focused our attention on the platelet, a peripheral cell that has been shown to be relevant in studying the physiologic and pathologic processing of APP ex vivo (14-22). 
In fact, platelets express the three major APP isoforms and their metabolites such as $\alpha$ APPs and $\mathrm{A} \beta$ (23-25).

The present study addresses the following major questions:

1. Is there any detectable $\alpha$-secretase candidate in platelets?

2. Is there any difference in $\alpha$-secretase between patients with $\mathrm{AD}$ and controls?

3. Is there any relationship between APP metabolites measured in platelets and in cerebrospinal fluid (CSF) of the same AD patient?

These results will help in understanding, in a more comprehensive way, ex vivo, one aspect of the complex events determining $\mathrm{AD}$ pathogenesis, eventually providing new means for targeted pharmacologic intervention.

\section{Materials and Methods}

Characteristics of the Subjects

This study was undertaken on 33 patients with probable $\mathrm{AD}$ and 26 age-matched neurologic control subjects recruited at the Neurological Department of University of Brescia. The diagnosis of probable AD was made according to National Institute of Neurological Disorders and Stroke-Alzheimer Disease and Related Disorders Association (NINDSADRDA) criteria. Exclusion criteria for all groups were head trauma, metabolic dysfunctions, hematologic diseases, alcohol abuse, drug abuse, delirium, mood disorders, treatment with acetylcholinesterase inhibitors (21), and with medications affecting platelet functions (anticoagulants, antiplatelet drugs, serotoninergic agonists-antagonists, and corticosteroids). All subjects included had a standardized clinical workup based on neurologic examinations, laboratory blood and urine analysis, neuropsychological assessment, and neuroimaging study (head CT and/or MRI). Before enrolment in the study, subjects or their legal caregivers completed an informed consent form after the nature and possible consequence of the study was explained.

Personnel who were blind for diagnosis carried out platelet preparation and subsequent analysis.

\section{Cerebrospinal Fluid}

CSF was obtained from 12 of 26 control subjects and 15 of $33 \mathrm{AD}$ patients by lumbar puncture with the patient sitting in the upright position. The CSF was immediately aliquoted in presence of a complete set of protease inhibitors (Complete Roche, Mannheim, Germany) and frozen at $-80^{\circ} \mathrm{C}$ until assayed. Protein concentration was measured by Bradford method and $4 \mu \mathrm{g}$ of total proteins were loaded on the gel (running gel: acrylamide 6\%) and electroblotted. The same amount of CSF proteins was processed in parallel in each sample for control subjects and $\mathrm{AD}$ patients. $\alpha$ APPs staining and quantitative analysis were performed as reported below (SDS-PAGE and Western blot analysis).

\section{Platelet Preparation}

Twenty-seven milliliters of blood were collected into $3 \mathrm{ml} \mathrm{3.8 \%} \mathrm{sodium} \mathrm{citrate} \mathrm{(in} \mathrm{presence} \mathrm{of} 136 \mathrm{mM}$ glucose), mixed gently, and centrifuged at $200 \times \mathrm{g}$ for $10 \mathrm{~min}$. The interval between blood drawing and the first centrifugation was $20-25 \mathrm{~min}$ at maximum. Platelet-rich plasma was separated from the blood cells using a plastic pipette, carefully avoiding the aspiration of the buffy coat. Platelets were collected by centrifugation at $1200 \times \mathrm{g}$ for $20 \mathrm{~min}$. Platelet pellets were washed twice with Tris- $\mathrm{HCl} 10 \mathrm{mM}$ pH 7.4 and resuspended in ice-cold lysis buffer containing Tris-HCl 10 mM, pH 7.4; EGTA 1 mM; phenylmethyl-sulfonyl fluoride $0.1 \mathrm{mM}$; and a complete set of protease inhibitors (Complete, Roche). Homogenates were then subjected to three rounds of freeze thawing and $15 \mathrm{sec}$ of sonication at $0^{\circ} \mathrm{C}$.

\section{Platelet Activation}

Platelet pellets were washed and resuspended in Tyrode's buffer according to Bush (26) and incubated with thrombin $(1 \mathrm{U} / \mathrm{ml})$ in the presence of $\mathrm{MgCl}_{2}$ and $\mathrm{CaCl}_{2}$ (activation condition) and in absence of both $\mathrm{MgCl}_{2}$ and $\mathrm{CaCl}_{2}$ (basal condition), stirring for $15 \mathrm{~min}$ at room temperature.

After activation, platelets were centrifuged at $1200 \times \mathrm{g}$ for $15 \mathrm{~min}$ and resuspended in lysis buffer (Tris-HCl 10 mM, pH 7.4; EGTA 1 mM; phenylmethyl-sulfonyl fluoride $0.1 \mathrm{mM}$; and a complete set of protease inhibitors [Complete, Roche]). The supernatants were desalted by using DG10 columns (Biorad, City, CA, USA) and the total proteins were separated on $6 \%$ SDS-PAGE and electroblotted to nitrocellulose membranes. $\alpha$ APPs staining and quantitative analysis were carried out as described below (SDS-PAGE and Western blot analysis).

\section{Platelet Fractionation}

Seventy microliters of platelet homogenates, prepared as reported, were centrifuged at $100,000 \times \mathrm{g}$ for $\mathrm{l} \mathrm{hr}$ at $4^{\circ} \mathrm{C}$ to separate membrane (pellet) and soluble (supernatant) fractions. The centrifugation step was repeated both for the soluble and the membrane fractions after resuspension in lysis buffer.

\section{RNA Extraction and RT-PCR Experiment}

Total cellular RNA was extracted from human platelets and from human cortex (kindly supplied by Dr. G. Battaglia, Besta Institute of Neurology, Milan, Italy) by acid-phenol method using an RNA extraction kit (Bio/RNA-X Cell, Bio/Gene).

One microgram of total RNA was used to perform the first strand cDNA synthesis using oligo(dt), M-MLV-RT, and RNase $\mathrm{H}$ Minus $200 \mathrm{U} / 1 \mu \mathrm{g}$ RNA (Promega, Madison, WI, USA). Following reverse transcriptase reaction, PCR amplification was 
performed by using specific primers for ADAM10 (284 bp): sense 5' AACACGAGAAGCTGTGATTGCCCA $3^{\prime}$, antisense 5' CAAGCCAGACCAAGTACGCCATC 3'. Commercial primers were used to amplify human GAPDH as housekeeping gene: sense $5^{\prime}$ ATG ACC CCT TCA TTG ACC 3', antisense 5' TGCTTCACCACCTTCTTG 3'. All PCR reactions were carried out by using Taq polymerase, $2.5 \mathrm{U}$ per sample (PE Biosystem, Faster City, CA, USA) in a programmable heating block (Gene Amp PCR System 9600, PE Biosystem, Faster City, CA, USA) with the following scheme cycles: denaturation $94^{\circ} \mathrm{C}$ for $1 \mathrm{~min}$; annealing $56^{\circ} \mathrm{C}$ for $1 \mathrm{~min}$; and extension $72^{\circ} \mathrm{C}$ for $1 \mathrm{~min}$ for 30 cycles. PCR products were electrophoresed on $2 \%$ agarose gel; gels were stained with ethidium bromide (EtBr) and photographed under UV light.

\section{Immunoprecipitation}

Fifty micrograms of human cortex proteins were incubated in RIA buffer containing NaCl $200 \mathrm{mM}$, ethylenediamine tetraacetic acid (EDTA) $10 \mathrm{mM}, \mathrm{Na}_{2} \mathrm{HPO}_{4}$ $10 \mathrm{mM}, \mathrm{NP}-400.5 \%$, and SDS $0.1 \%$ in a final volume of $200 \mu \mathrm{l}$ with antibodies against ADAM10 (dilution 1:100; Prosci Inc, Poway, CA, USA) overnight at $4^{\circ} \mathrm{C}$, shaking. Protein A-agarose beads $(5 \mathrm{mg} /$ tube; SantaCruz Biotechnology, Santa Cruz, CA, USA), washed in the same buffer, were added and incubation continued for $1 \mathrm{hr}$. The beads were collected by centrifugation and washed three times with RIA buffer. Sample buffer for SDS-PAGE was added and the mixture was heated for $3 \mathrm{~min}$. Beads were pelletted by centrifugation and a volume of supernatants was applied to SDS-PAGE 8\%; ADAM10 was recognized by means of its specific antibody. When indicated in the text, samples were incubated with protein A-agarose beads in absence of the primary antibody to test for unspecific precipitation.

\section{Analysis of Protein Glycosylation}

Aliquots of $100 \mu \mathrm{g}$ platelet proteins were treated with or without $\mathrm{IU}$ N-glycosidase F for $5 \mathrm{hr}$ at $37^{\circ} \mathrm{C}$ in the presence of buffer recommended by the supplier (Roche, Mannheim, Germany); sialic acids and $\mathrm{O}$-glycosylated residues were digested sequentially. Neuraminidase (17 mU; Sigma-Aldrich, Steinheim, Germany) was added to $100 \mu \mathrm{g}$ of total platelet pro-

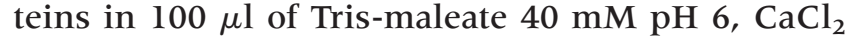
$2.25 \mathrm{mM}$, leupeptine $200 \mu \mathrm{g} / \mathrm{ml}$ (Sigma-Aldrich) and incubated for $4 \mathrm{hr}$ at $37^{\circ} \mathrm{C}$. Fifty microliters were removed. O-glycanase $2 \mathrm{mU}$ (Roche) and leupeptine (200 $\mu \mathrm{g} / \mathrm{ml}$; Sigma-Aldrich) were added to the remaining $50 \mu \mathrm{l}$ and incubated for $17 \mathrm{hr}$ at $37^{\circ} \mathrm{C}$.

Control digestion (no enzyme added) demonstrated that samples did not undergo spontaneous degradation during incubations.

\section{SDS-PAGE and Western Blot Analysis}

Cerebrospinal fluid, platelets, and human cortex proteins were separated in $6 \%$ or $8 \%$ SDS-PAGE as indicated, electroblotted to nitrocellulose membranes in a buffer containing $0.025 \mathrm{M}$ Tris- $\mathrm{HCl}, 0.192 \mathrm{M}$ glycine, $20 \%$ methanol, $\mathrm{pH} 8.3$ at $230 \mathrm{~mA}$ for $2 \mathrm{hr}$ and $30 \mathrm{~min}$. After blocking with $10 \%$ nonfat milk, immunostaining reactions were performed using the following antibodies: antiserum (pAb) to C-terminal of ADAM10 (dilution: 1:2000); clone 6E10, monoclonal antibody (mAb) anti-amyloid beta protein (aa 1-16 of A $\beta$ peptide; Chemicon, Tamecula, CA, USA; dilution 1:1000); clone AC40 for actin (SigmaAldrich; dilution: 1:3000); clone 22C11, mAb raised against $\mathrm{N}$-terminal domain of APP (Chemicon; dilution 1:1000). Peroxidase-conjugated secondary antibodies (Sigma-Aldrich) were used.

Blots were developed with enhanced chemiluminescence (Amersham-Pharmacia Biotech, Buckinghamshire, UK) and exposed to films (AmershamPharmacia Biotech).

\section{Data Analysis and Statistical Evaluation}

Quantitative analysis of Western blot analysis was performed by means of computer-assisted imaging (Quantity-One System, Biorad). Statistical evaluations were performed according to one-way analysis of variance (ANOVA) followed by Bonferroni as post hoc comparison test.

\section{Results \\ Identification and Characterization of ADAM10 in Human Platelets}

A representative RT-PCR analysis performed using specific primers for ADAMI0 on RNA extracted from control platelets and from human cortex is shown in Figure 1. Amplification of a housekeeping gene, such as GAPDH, was also used.

The presence of a specific transcript for ADAM10 at $284 \mathrm{bp}$ is shown both in platelets (Plt) and human

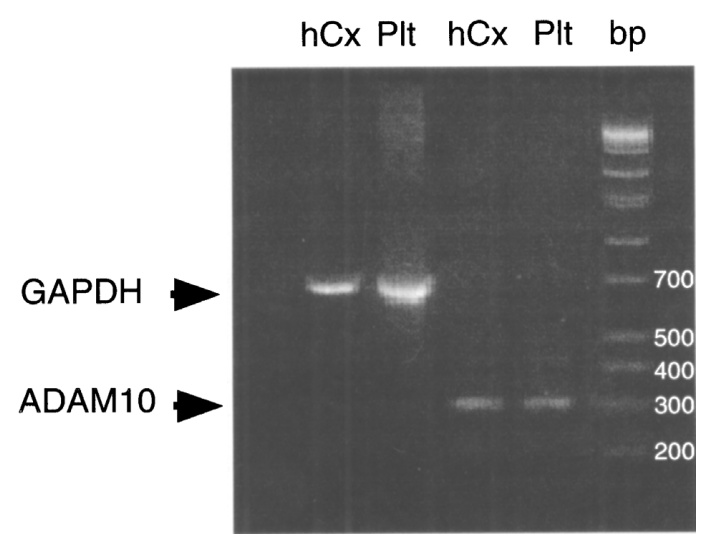

Fig. 1. Expression of ADAM10 in human platelets and human cortex. Total RNA was extracted from platelets and human cortex, transcribed into CDNA, and amplified by PCR with ADAM10-specific oligonucleotide primers. Single transcript of the expected size was obtained both in platelets (Plt) and human cortex $(\mathrm{hCx})$. GAPDH expression was estimated as internal control for each sample. Bp markers are reported in the right-most lane. 
cortex (hCx). A representative immunoblot analysis of platelet ADAM10 in a control subject is shown in Figure 2A. Staining with an ADAM10 specific antibody revealed a major band at $68 \mathrm{kDa}$. Immunoreactivity of the $68 \mathrm{kDa}$ band increases with the platelet protein concentration (Fig. 2A). No unspecific signal was obtained reacting nitrocellulose with the secondary antibody alone, thus confirming the specificity of the $68-\mathrm{kDa}$ band (rightmost lane). WB analysis performed in total human cortex homogenates, using the same polyclonal antibody,

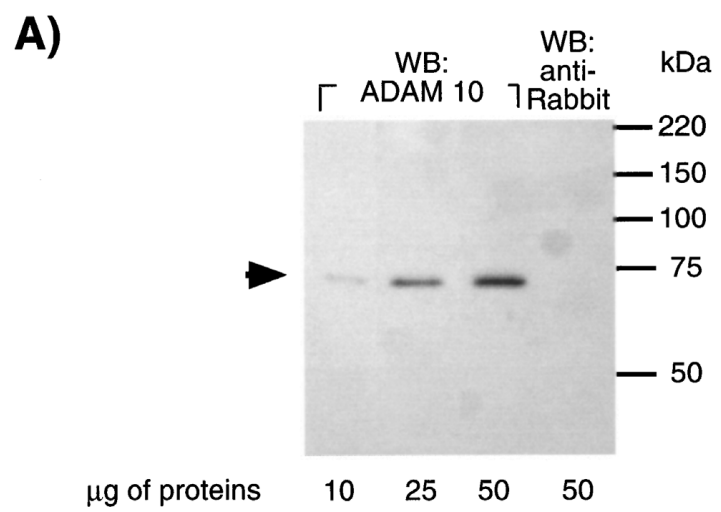

B)

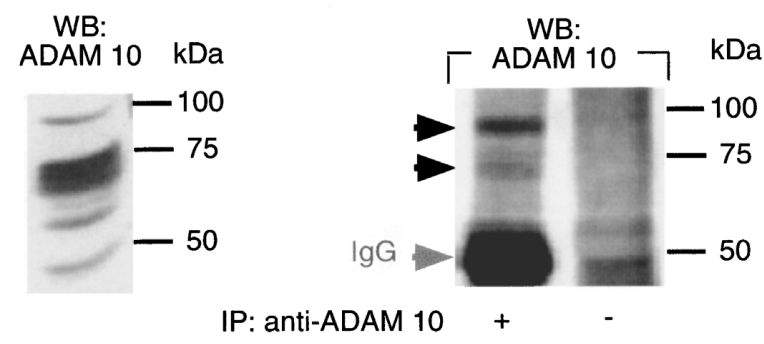

Fig. 2. WB analysis of ADAMI0 in human cortex and human platelets. (A) Representative WB analysis of ADAM10 in whole platelet homogenate of a control subject. Increasing protein concentrations were loaded on gel ( $8 \%$ SDS-PAGE). The arrow shows the migration of the 68 -kDa ADAM10 immunoreactive band. No other bands are present at higher MW. No unspecific signal was obtained by incubating nitrocellulose with the secondary antibody alone (rightmost lane). Molecular weight markers are reported on the right. (B) Left panel: Representative WB analysis of ADAM10 in human cortical homogenate of a control subject. Fifty micrograms of proteins were loaded on $8 \%$ acrylamide gel. Molecular weight markers are reported on the right. Right panel: Representative WB analysis of ADAM10 in human cortex after immunoprecipitation: $50 \mu \mathrm{g}$ of human cortex proteins were incubated in presence $(+)$ and in absence $(-)$ of pAb anti-ADAM10 in RIA buffer and then precipitated with protein A-agarose beads. The immunoprecipitated samples were then loaded into $8 \%$ SDSPAGE and recognized with pAb anti-ADAM10. Two forms are present (arrowheads), enriched in the immunocomplex in comparison with WB analysis (left panel). A major band is present at $85 \mathrm{kDa}$, corresponding to the precursor protein, and a second band at $68 \mathrm{kDa}$, corresponding to the mature form of the protein. They represent two specific forms because they are not detected when the total protein was incubated in the absence of antibody $(-)$. Molecular weight markers are reported on the right. revealed several immunoreactive bands (Fig. 2B, left panel). Therefore, human cortical samples were immunoprecipitated to better detect specific ADAM10 immunoreactive proteins (Fig. 2B, right panel). Under these conditions (Fig.2B, right panel, lane + ), two major bands are visible: one corresponds to the enzyme with the prodomain ( $85 \mathrm{kDa}$; upper arrow) and the second one, at $68 \mathrm{kDa}$, corresponds to the major band observed in platelets. As expected, a major signal, corresponding to IgG, is present at about $50 \mathrm{kDa}$. An aliquot of the sample was precipitated with protein $\mathrm{A}$ in absence of the primary antibody to test for unspecific precipitation (Fig. 2B, right panel, lane -).

The glycosylation state of platelet ADAM10 immunoreactive band was tested. Figure 3 shows a representative immunoblot analysis performed with anti-ADAM10 on platelet homogenates before and after treatment with $\mathrm{N}$-glycosidase $\mathrm{F}$, and after incubation with neuraminidase and O-glycanase. ADAM10 undergoes a downward bandshift of roughly $6 \mathrm{kDa}$ in its apparent $\mathrm{MW}$ when treated with N-glycosidase F (Fig. 3A). Neuraminidase and

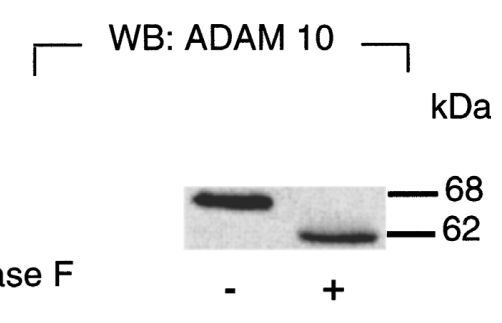

B)
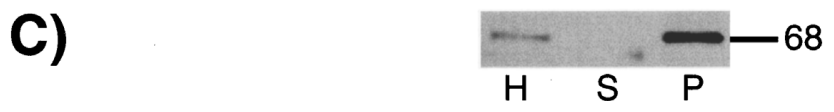

Fig. 3. Biochemical characterization of ADAM10 in human platelets. (A) Analysis of ADAM10 N-glycosylation in control platelets: $100 \mu \mathrm{g}$ of total platelet proteins were incubated with $(+)$ and without $(-) \mathrm{N}$-glycosidase $\mathrm{F}$, loaded on $8 \%$ acrylamide gels and ADAM10 identified by immunoblotting. $\mathrm{N}$-glycosidase F treatment causes a downward bandshift of $6 \mathrm{kDa}$ of the ADAM10 immunoreactive band. Molecular weight markers are reported on the right. (B) Analysis of ADAMI0 O-glycosylation in control platelets: $100 \mu \mathrm{g}$ of total platelet were incubated with $(+)$ or without $(-)$ neuraminidase. $50 \mu \mathrm{g}$ were removed and further incubated with $(+)$ or without $(-)$ $\mathrm{O}$-glycanase. Twenty micrograms of total proteins were loaded on $8 \%$ acrylamide gels and ADAM10 identified by immunoblotting. O-deglycosylation experiments failed to produce a shift of ADAM10 immunoreactive band. Molecular weight markers are reported on the right. (C) Western blot analysis performed with an antibody specific for ADAM10 in platelet subcellular fractions. Immunoreactivity is present in platelet homogenate $(\mathrm{H})$ and in particulate $(\mathrm{P})$, but not in the soluble fraction $(\mathrm{S})$. 
O-glycanase treatment (Fig. 3B) failed to produce any downward shift of the ADAM10 band, suggesting the presence of $\mathrm{N}$ - but not $\mathrm{O}$-glycosylation sites in protein, as previously described in transfected cell systems (10). When different subcellular compartments (Fig. 3C) were probed with the same antibody, the ADAM10 immunoreactive band was enriched in the membrane fraction $(\mathrm{P})$.

\section{Expression of ADAM10 in Platelets of Controls and $A D$ Patients}

We then quantified, by means of Western blot analysis, the level of ADAM10 in platelets obtained from control subjects and AD patients. Table l shows the demographic characteristics of patients included in the study.

Figure $4 \mathrm{~A}$ shows the results of a representative double immunostaining for ADAM10 and $\beta$-actin in whole platelet homogenate of two control subjects and two AD patients.

Fifteen micrograms of total proteins was loaded on gel. The signal for $\beta$-actin was linear in a protein range of 5-50 $\mu \mathrm{g}$ and with a range of antibody dilution from 1:1000 to 1:10000. An anti-ADAM10 dilution of 1:2000 and anti- $\beta$ actin of 1:3000 was used.

The densitometric analysis of immunoblots revealed no significant differences in the actin immunoreactivity among the two experimental groups, whereas a decrease in immunostaining for ADAM10 was found in $A D$ subjects. The ratio between ADAM10 and $\beta$-actin immunoreactivity was determined and the relative scattergram is shown in Figure 4B. A statistically significant reduction in the ratio of $\mathrm{ADAM} 10 / \beta$-actin immunoreactivity was present in AD subjects when compared to controls (controls, $n=26$; $\mathrm{AD}, n=33 ; p<0.0001$ ). To further confirm clinical probable AD diagnosis, for all subjects included, whole platelet homogenates were processed by means of Western blot analysis with mAb 22C11, recognizing all APP forms: APP form ratio (APPr) given as the ratio between APP immunoreactive band at $130 \mathrm{kDa}$ and APP form at

Table 1. Demographic and clinical variables of the sample

\begin{tabular}{lcc}
\hline Variable & Controls & $\begin{array}{c}\text { Alzheimer } \\
\text { Patients }\end{array}$ \\
\hline Cases $(N)$ & 26 & 33 \\
Age (mean \pm SD) & $63.19 \pm 6.10$ & $68.15 \pm 6.18$ \\
Gender (M/F) & $9 / 17$ & $13 / 20$ \\
MMSE (mean \pm SD) & $29.28 \pm 1.1$ & $18.0 \pm 3.7$ \\
APP ratio (mean \pm SD) & $0.90 \pm 0.29$ & $0.31 \pm 0.19 *$
\end{tabular}

${ }^{*} p<0.001$ 
A)

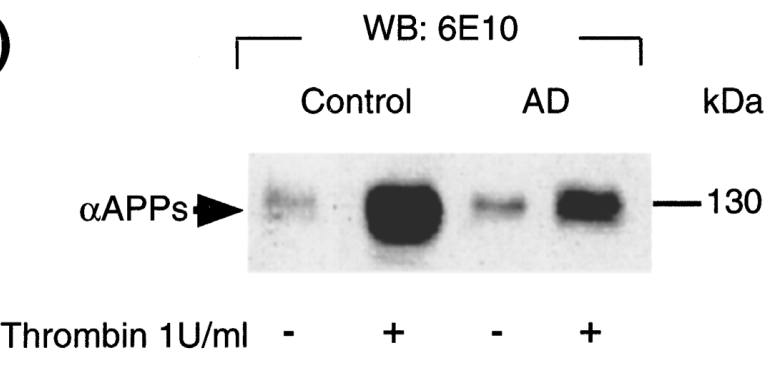

B)

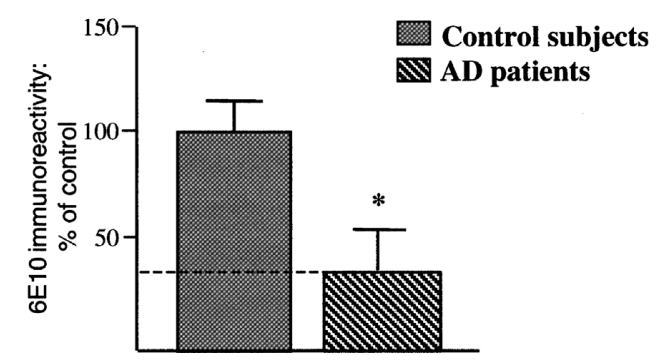

Fig. 5. Quantitative analysis of $\alpha$ APPs in platelets and CSF of control subjects and AD patients. (A) Representative Western blot analysis performed on supernatants of unstimulated and activated platelets from AD patients and control subjects with mAb 6E10, recognizing $\alpha$ APPs. Total proteins released from resting $(-)$ platelets and from platelets activated with thrombin $(+)$ were desalted and loaded into a $6 \%$ acrylamide gel. A $130-\mathrm{kDa}$ form immunoreactive for $6 \mathrm{E} 10$ is present (arrowhead). Apparent molecular weight is reported on the right. (B) Quantitative analysis of 6E10 Western blot from platelet supernatants are reported (control, $n=12 ; \mathrm{AD}$, $n=15$ ). Immunoreactive bands were measured by computerassisted imaging. A significant reduction in the levels of 130-kDa form was observed in AD patients $(p<0.001)$.

thrombin-induced release of $\alpha$ APPs was markedly lower in AD patients when compared to controls. The immunoreactivity of $\alpha$ APPs bands in thrombinactivated platelets was quantified by image analysis. As shown in Figure 5B, a highly significant difference was found between $\mathrm{AD}$ and control samples $(p<0.001)$.

It has been previously shown that both familial and sporadic AD patients show reduced levels of $\alpha$ APPs in CSF (27-29). Therefore, we addressed the questions whether the reduction of thrombininduced release of $\alpha$ APPs observed in AD platelets is associated with CSF changes in $\alpha$ APPs, thus reflecting central abnormalities of APP metabolism.

To answer this question, we measured $\alpha$ APPs levels in CSF of the same pool of AD patients and control subjects who were tested for platelet $\alpha$ APPs. CSF samples $(4 \mu \mathrm{g}$ of total proteins in a volume ranging from $10-15 \mu \mathrm{l}$ ) were probed with mAb 6E10. Figure 6A shows a representative Western blot analysis performed with mAb 6E10 in two control subjects and two AD patients. The immunoreactivity of the $110-\mathrm{kDa}$ band, corresponding to $\alpha$ APPs form in neuronal cells, was significantly reduced in CSF of AD patients when compared to control

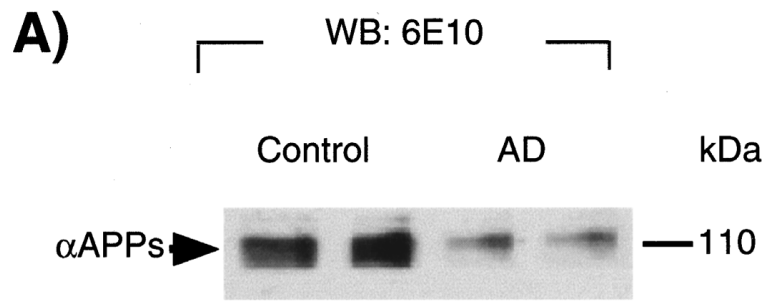

B)

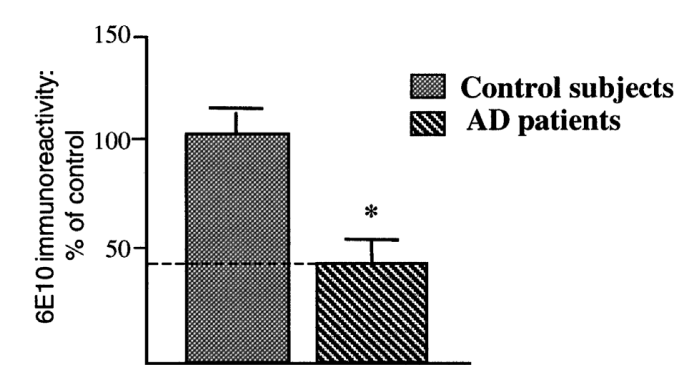

Fig. 6. Quantitative analysis of $\alpha$ APPs in CSF of control subjects and AD patients. (A) Representative Western blot analysis performed on CSF collected from two control subjects and two AD patients with mAb 6E10, recognizing $\alpha$ APPs. A $110-\mathrm{kDa}$ form immunoreactive for 6E10 is present (arrowhead). Apparent molecular weight is reported on the right. (B) Quantitative analysis of $6 \mathrm{E} 10$ western blot are reported (control, $n=$ 12; $\mathrm{AD}, n=15$ ) Immunoreactive bands were measured by computer-assisted imaging. A significant reduction in the levels of $110-\mathrm{kDa}$ form was observed in AD patients $(p<0.05)$.

subjects, as confirmed by quantitative analysis reported in Figure 6B $(p<0.05)$.

\section{Discussion}

The main finding reported herein is that platelets show the expression of the $\alpha$-secretase candidate ADAMIO and that levels of ADAMI0 are significantly decreased in platelets of AD patients when compared to control subjects. In addition, because ADAM10 has been shown in several in vitro systems to be capable of metabolizing APP we measured, in platelets of control and AD patients, levels of the major $\alpha$-secretase metabolite, $\alpha$ APPs.

We show that a significant decrease in thrombinstimulated release of $\alpha$ APPs occurs in platelets of AD patients, compared to controls, and this is paralleled by qualitatively and quantitatively similar decreases of $\alpha$ APPs levels measured in the CSF of the same patients.

The identification of ADAMI0 in platelets, although expected, has never been reported before.

ADAMIO has been reported to be the most likely physiologic adult brain $\alpha$-secretase (30). Moreover, ADAMI0 appears to colocalize, in brain tissue, best with $\beta$-secretase (BACE) and APP, thus suggesting that it represents an importantamyloidogenic secretase (30). Our results showed that platelets express the same transcript for ADAM10 
as the human cortex. In platelets, however, a major band at $68 \mathrm{kDa}$ is found, whereas in cortex there are two forms at apparent molecular weights of 85 and $68 \mathrm{kDa}$.

Previous studies performed in transfected cell systems (10) identified two ADAMI0 forms at apparent MWs of 85 and $68 \mathrm{kDa}$, and proposed that the 85 $\mathrm{kDa}$ form represents the proenzymatic form. The finding that in platelets only the $68 \mathrm{kDa}, \mathrm{N}$-glycosylated form was identified might depend on the fact that platelets are pseudocells derived from maturation of megakaryocytes. It may be hypothesized, however, that megakaryocytes contain both forms, whereas platelets may contain only the mature $68 \mathrm{kDa}$ form of the enzyme.

The observation that ADAM10 levels are markedly reduced in AD patients has several implications; ADAM10 is involved in basal nonstimulated processing of APP (10). Because $\alpha$ - and $\beta$-secretase pathways appear to be mutually exclusive, it is likely that reduction of ADAMI0 allows for $\beta$-secretase amyloidogenic cleavage of the protein. This hypothesis was recently supported by the finding that increased $\alpha$-secretase activity and $\alpha$ APPs release after cholesterol reduction in neural cell lines results in a decreased secretion of both $\mathrm{A} \beta$ and $\beta$ APPs (11). This effect is probably due to reduced substrate availability for $\beta$-secretase cleavage. Accordingly, our study shows that thrombin-induced $\alpha$ APPs release from platelets of $\mathrm{AD}$ patients is reduced when compared to controls.

The biochemical mechanisms responsible for $\alpha$ APPs and $\mathrm{A} \beta$ formation in platelets are not fully understood, although several groups have reported abnormalities in these parameters in AD subjects (15-17). APP metabolites' production and release from platelets has been linked to two important intracellular pathways-cyclooxygenase (COX) and PKC activation (31)-suggesting that multiple pathways can be ascribed to the observed decreased of thrombininduced $\alpha$ APPs release in AD patients. It may be proposed that decreased levels of ADAMIO as well as a modification of the intracellular cascade might modulate APP trafficking and processing (31). Whether these different mechanisms converge or act in parallel to affect APP metabolism remains to be established.

All data presented here were obtained ex vivo in AD patients using an easily accessible peripheral cell (platelets).

The use of a peripheral cell to study a molecular aspect of neuropathology may raise some concerns, primarily with the feasibility of a peripheral cell mirroring biochemical pathways occurring in the central nervous system. However, the appropriateness of using platelets is in the multiple similarities between platelets and neuronal cells: platelets store and release neurotransmitters and bear appropriate transporters and receptors normally expressed by neuronal cells $(18,32)$. These similarities, although provocative, underscore the use of platelets for the search of clinical markers for either neuropsychiatric or neurologic disorders. Our findings that a qualitative and quantitative similar alteration of $\alpha$ APPs levels is present both in platelets and CSF of the same patient are consistent with this hypothesis. In fact, although a reduction of CSF $\alpha$ APPs levels in AD patients has been previously reported (27-29), our results show a possible correlation between peripheral and central compartment in the same subject.

In conclusion, our findings show a reduction of ADAM10 levels in vivo, indicating that ADAM10 is one of the major players in the molecular pathogenesis of AD and supports the hypothesis that increasing its activity/expression might prove beneficial for $\mathrm{AD}$.

\section{Acknowledgments}

This work is supported by CNR grants \# 98.01097.CT14 and \# 99.01234.CT14 to M.D.L., MURST 40\% 1999-2000, $\mathrm{N}^{\circ}$ 9906158271-004 to M.D.L., and Progetto Alzheimer Min. Sanita'20012003 to F.C. and M.D.L.

\section{References}

1. Sisodia SS. (1992) Beta-amyloid precursor protein cleavage by a membrane-bound protease. Proc. Natl. Acad. Sci. U.S.A. 89: 6075-6079.

2. Tomita S, Kirino Y, Suzuki T. (1998) Cleavage of Alzheimer's amyloid precursor protein (APP) by secretases occurs after O-glycosylation of APP in the protein secretory pathwayIdentification of intracellular compartment in which APP cleavage occurs without using toxic agents that interfere with protein metabolism. J. Biol. Chem. 273: 6277-6284.

3. Weidemann A, Konig G, Bunke D, et al. (1989) Identification, biogenesis, and localization of precursors of Alzheimer's disease A4 amyloid protein. Cell 57: 115-126.

4. Haass C, Selkoe DJ. (1993) Cellular processing of betaamyloid precursor protein and the genesis of amyloid betapeptide. Cell 75: 1039-1042.

5. Walter J, Capell A, Hung AY, et al. (1997) Ectodomain phosphorylation of beta-amyloid precursor protein at two distinct cellular locations. J. Biol. Chem. 272: 1896-1903.

6. Buxbaum JD, Liu KN, Luo X, et al. (1998) Evidence that tumor necrosis factor alpha-converting enzyme is involved in regulated alpha-secretase cleavage of the Alzheimer amyloid precursor protein. J. Biol. Chem. 273: 27765-27767.

7. Nitsch RM, Slack BE, Wurtman RJ, et al. (1992) Release of Alzheimer amyloid precursor derivatives stimulated by activation of muscarinic acetylcholine receptors. Science 258: 304-307.

8. Koike H, Tomioka S, Sorimachi H, et al. (1999) Membraneanchored metalloprotease MDC9 has an alpha-secretase activity responsible for processing the amyloid precursor protein. Biochem. J. 343: 371-375.

9. Nelson KK, Schlondorff J, Blobel CP. (1999) Evidence for an interaction of the metalloprotease-disintegrin tumor necrosis factor alpha convertase (TACE) with mitotic arrest deficient 2 (MAD2), and of the metalloprotease-disintegrin MDC9 with a novel MAD2-related protein, MAD2beta. Biochem. J. 343: 673-680.

10. Lammich S, Kojro E, Postina R, et al. (1999) Constitutive and regulated $\alpha$-secretase cleavage of Alzheimer's amyloid precursor protein by a disintegrin metalloprotease. Proc. Natl. Acad. Sci. U.S.A. 96: 3922-3927.

11. Kojro E, Giml G, Lammich S, Marz W, Fahrenholz F. (2001) Low cholesterol stimulates the nonamyloidogenic pathway 
by its effect on the $\alpha$-secretase. Proc. Natl. Acad. Sci. U.S.A. 98: 5815-5820.

12. Slack BE, Ma LK, Seah CC. (2001) Constitutive shedding of the amyloid precursor protein ectodomain is up-regulated by tumour necrosis factor-alpha converting enzyme. Biochem. J. 357: 787-794.

13. Parvathy S, Hussain I, Karran EH, Turner AJ, Hooper NM. (1998) Alzheimer's amyloid precursor protein alpha-secretase is inhibited by hydroxamic acid-based zinc metalloprotease inhibitors: Similarities to the angiotensin converting enzyme secretase. Biochemistry 37: 1680-1685.

14. Di Luca M, Pastorino L, Cattabeni F, et al. (1996) Abnormal pattern of platelet APP isoforms in Alzheimer disease and Down syndrome. Arch. Neurol. 53: 1162-1166.

15. Davies TA, Long HJ, Tibbles HE, et al. (1997) Moderate and advanced Alzheimer's patients exhibit platelet activation differences. Neurobiol. Aging 18: 155-162.

16. Davies TA, Long HJ, Sgro K. (1997) Activated Alzheimer disease platelets retain more beta amyloid precursor protein. Neurobiol. Aging 18: 147-153.

17. Rosenberg RN, Baskin F, Fosmire JA, et al. (1997) Altered amyloid protein processing in platelets of patients with Alzheimer disease. Arch. Neurol. 54: 139-144.

18. Bush AI, Tanzi RE. (1998) Alzheimer disease-related abnormalities of amyloid beta precursor protein isoforms in the platelets-the brain delegates in the periphery? Arch. Neurol. 55: 1179-1180.

19. Di Luca M, Pastorino L, Bianchetti A, et al. (1998) Differential pattern of platelet APP isoforms: An early marker for Alzheimer disease. Arch. Neurol. 55: 1195-1200.

20. Baskin F, Rosenberg RN, Iyer L, et al. (2000) Platelet APP isoform ratios correlate with declining cognition in AD. Neurology 54: 1907-1909.

21. Borroni B, Colciaghi F, Pastorino L, et al. (2001) Amyloid precursor protein in platelets of patients with Alzheimer diseaseEffect of acetylcholinesterase inhibitor treatment. Arch. Neurol. 58: $442-446$.
22. Padovani L, Pastorino B, Borroni et al. (In press) Amyloid precursor protein in platelets: A peripheral marker for the diagnosis of sporadic AD. Neurology.

23. Van Nostrand WE, Schmaier AH, Farrow JS, Cunningham DD. (1990) Protease nexin II (amyloid beta protein precursor): A platelet $\alpha$-granule protein. Science 248: 745-748.

24. Li QX, Whyte S, Tanner JE, et al. (1998) Secretion of Alzheimer's disease A beta amyloid peptide by activated human platelets. Lab. Invest. 78: 461-469.

25. Abraham CR, Marshall DC, Tibbles HE, et al. (1999) Platelets and DAMI megakaryocytes possess beta-secretase-like activity. J. Lab. Clin. Med. 133: 507-515.

26. Bush AI, Martins RN, Rumble B, et al. (1990) The amyloid precursor protein of Alzheimer's disease is released by human platelets. J. Biol. Chem. 265: 15977-15983.

27. Lannfelt L, Basun H, Wahlund LO, et al. (1995) Decreased alpha-secretase-cleaved amyloid precursor protein as a diagnostic marker for Alzheimer's disease. Nat. Med. 1: 829-832.

28. Almkvist O, Basun H, Wagner S, et al. (1997) Cerebrospinal fluid levels of alpha-secretase-cleaved soluble amyloid precursor protein mirror cognition in a Swedish family with Alzheimer disease and a gene mutation. Arch. Neurol. 54: 641-644.

29. Sennvik K, Fastbom J, Blomberg M, et al. (20000 Levels of $\alpha$ and $\beta$ secretase cleaved amyloid precursor protein in the cerebrospinal fluid of Alzheimer's disease patients. Neurosci. Lett. 278: 169-172.

30. Marcinkiewicz M, Seidah NG. (2000) Coordinated expression of $\beta$-amyloid precursor protein and putative $\beta$-secretase BACE and $\alpha$-secretase ADAM10 in mouse and human brain. J. Neurochem. 75: 2133-2143.

31. Skovronsky DM, Lee VMY, Praticò D. (2001) Amyloid precursor protein and amyloid b peptide in human platelets. $J$. Biol. Chem. 286: 17036-17043.

32. Ferrarese C, Begni B, Canevari C, et al. (2000) L. Glutamate uptake is decreased in platelets from Alzheimer's disease patients. Ann. Neurol. 47: 641-643. 